\title{
El delito de peculado en la jurisprudencia
}

\section{The Crime of Embezzlement in Jurisprudence}

Carlos Alberto Juárez Muñoz* https://orcid.org/ 0000-0003-4385-5300

* Abogado. Fiscal Provincial Penal Titular de Lima. Perú.

Correo Electrónico: c_juarezm@hotmail.com
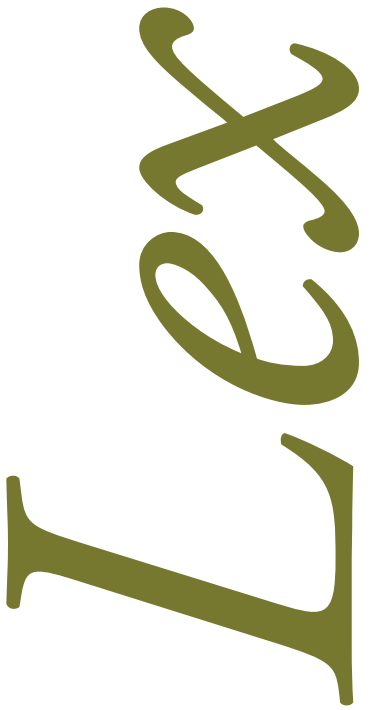
(c) (C) Los autores. Artículo publicado por la Revista Lex de la Facultad de Derecho y Ciencias Políticas de la Universidad Alas 


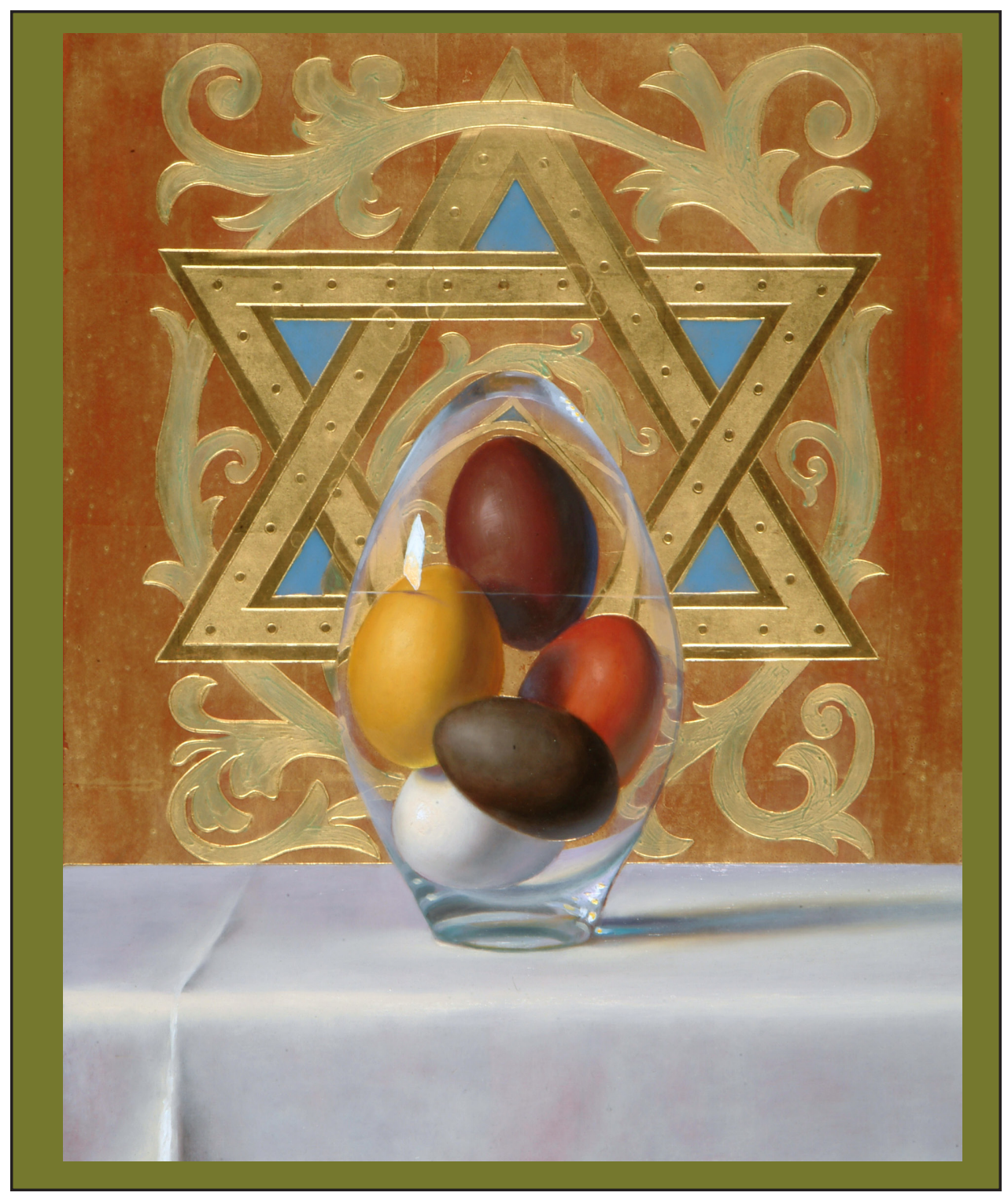

Origen del Mundo $46 \mathrm{~cm}$ X $33 \mathrm{~cm}$ (23kt gold water gilt oil on wood)

David Hewson (EEUU, 1966) www.davidhewsonart.com 


\title{
RESUMEN
}

La ubicación del delito de peculado en el Código Penal, el conglomerado de tipos penales que agrupa el Sistema Administración Pública, la mención del individuo que interviene en su comisión y la relación competencial de este con el objeto de apropiación, son particularidades de un delito especial, por cuya razón, para ser considerado sujeto activo de este delito la norma, de todas las personas que integran la comunidad nacional, identifica a uno en particular con características definidas, roles, servicios, prestaciones y competencias contemplados en el artículo 425 del Código Penal, sin embargo, el delito de peculado no deja de ser uno de infracción de deber, ya que, la relación del sujeto activo y el bien objeto de protección se encuentran debidamente normados. Las particularidades en mención, han servido a la Corte Suprema al votar por una definición amplia del atributo normativo "funcionario público". Por otra parte, el tipo penal del delito de peculado no fija parámetros cuantitativos mínimos para sancionar la conducta del agente público que, por ejemplo, utiliza cuatro hojas del papel que se le ha asignado a un abogado para desempeńar su función, en un escrito de defensa particular, lo que ha dado lugar a que se inaplique la disposición que sanciona el delito de peculado.

Palabras claves: delito de peculado, infracción de deber, funcionario público, funcionario de hecho o de facto, montos insignificantes.

\begin{abstract}
The location of the crime of embezzlement in the Criminal Code, the conglomerate of criminal types that groups the Public Administration System, the mention of the individual who intervenes in its commission and the competent relationship of this with the object of appropriation, are peculiarities of a special crime, for which reason, to be considered an active subject of this crime, the norm, of all the people that make up the national community, identifies one in particular with defined characteristics, roles, services, benefits and competencies contemplated in article 425 of the Penal Code However, the crime of embezzlement is still one of an infringement of duty, since the relationship of the active subject and the object of protection are duly regulated. The particularities in question have served the Supreme Court by voting for a broad definition of the normative attribute "public official". On the other hand, the criminal type of the crime of embezzlement does not establish minimum quantitative parameters to punish the conduct of the public agent who, for example, uses four sheets of the role that a lawyer has been assigned to carry out his function, in a brief of private defense, which has led to the inapplication of the provision that punishes the crime of embezzlement.
\end{abstract}

Key words: crime of embezzlement, breach of duty, public official, de facto or de facto official, insignificant amounts. 


\section{INTRODUCCIÓN}

Esencialmente, el delito de peculado se encarga de sancionar la disposición -sin derecho- de los bienes públicos por parte del sujeto a quien se le confió su administración, percepción o custodia, entorpeciendo de este modo, el destino al interés público al cual están afectos, por cuya desposesión el Estado ve afectado un valor patrimonial asignado a la organización y, debido al componente humano que lo hace y a las normas que regulan su actuación, se contravienen deberes de una función pública específica.

Ante esto, la revisión de los recursos de nulidad y las denuncias casacionales vistas en última instancia del sistema judicial, advertimos que en los casos de alta cuantía o de altos funcionarios estatales, la Corte Suprema ha confrontado este delito con las conductas lesivas del patrimonio de todos los peruanos, desarrollando figuras comentadas por la doctrina como el llamado título habilitante, la relación funcionarial con el objeto material del delito y el funcionario de facto o de hecho, con lo cual se han resuelto condenas en casos emblemáticos con figuras públicas como el ex presidente Alberto Fujimori Fujimori y el ex asesor presidencial Vladimiro Montesinos Torres, así también, en supuestos de apropiaciones de montos irrisorios, la decisión ha sido sustentada en el recurso al principio de mínima intervención, entre otros, para dictar la absolución, todo lo cual ha servido de material para el comentario realizado.

\section{EL DELITO DE PECULADO, UN DELITO ESPECIAL Y DE INFRACCIÓN DE DEBER}

La Administración Pública nacional, tiene en el delito de peculado a su defensor, el cual cuenta entre sus elementos típicos, al funcionario o servidor público que se apropia o utiliza los bienes públicos que tiene a su cargo ${ }^{1}$, por lo tanto, se trata de un comportamiento que sucede al interior de la Administración Pública por parte de un sujeto que presta servicios para ella. La mención clara y expresa del funcionario o servidor público en esta figura delictiva excluye al común de las personas y confiere

1. Carlos Mir, Delitos contra la Administración Pública en el Nuevo Código Penal (Barcelona: José María Bosh editor, 2000), p. 290. 
a este delito su carácter de especial en los que, a diferencia de los de dominio, tiene un deber (al que se encuentra legalmente obligado el sujeto) que surge de una institución jurídica, como la razón que fundamenta el delito. Se trata entonces, de un delito especial porque la acción típica única y solamente, está contemplada para una persona puntual que ostenta en relación al bien jurídico protegido una posición relevante (por su carácter competencial) y que es llamada a cumplir un rol legalmente definido en nuestro ámbito social.

Esta dualidad para identificar al delito de peculado también es advertida por Reaño ${ }^{2}$ citado por la Corte Suprema de Justicia, cuando expresa que el delito de peculado es un delito especial porque típicamente restringe los contornos de la autoría a determinados sujetos cualificados -en este caso, de funcionarios y servidores públicos-, pero, al mismo tiempo, se trata de un delito de infracción de deber porque el fundamento de la responsabilidad penal a título de autor reside en el quebrantamiento de un deber positivo asegurado institucionalmente.

Del mismo modo, la Corte Suprema ha sancionado que «[e]l delito de peculado por apropiación, materialmente, es uno de infracción de deber, en cuya virtud las relaciones entre el agente oficial y el bien están definidas esencialmente por medio de un status del autor en relación con el bien, que se encuentra estrechamente vinculado a contextos normados -su responsabilidad o autoría se determina por medio de ese status, de una competencia institucional, no por medio de su ámbito de organización-»³.

En ese sentido, el término funcionario o servidor público en realidad es el elemento personal que identifica al delito de peculado - y a otros de su especie- y que, a su vez, delimita de todos los autores posibles, a un número singular y único. La expresión "funcionario o servidor público», en nuestro contexto, podría ser definido como la posición que ostenta una persona en la sociedad en relación a la prestación que realiza para el servicio público del Estado o sus dependencias, cuya actuación (atribuciones) se encuentra sujeta al cumplimiento de determinados deberes regulados por ley, empero, que, a su vez sirve para identificar a un tipo de delito especial, por razón de las calidades del sujeto activo. La calidad de funcionario o servidor público, está estrechamente vinculado a contextos regulados (padres, tutores, funcionario)- es decir, a instituciones- preformados y a lo sumo disponibles dentro de estrechos límites ${ }^{4}$, en ese sentido, el peculado es un delito de infracción de deber, puesto que la responsabilidad del funcionario o servidor público, "aparece a causa de la lesión de deberes de cuidado de un bien " 5 , debido a que los márgenes de actuación en relación al objeto de tutela penal a que está sujeto el funcionario o servidor público están regulados normativamente.

2. José Reaño. "La administración de caudales por delegación de competencias funcionariales". (Citado en Corte Suprema de Justicia. Sala Penal Permanente. (16 de agosto de 2016), R.N. No 615-2015-Lima. MP. Josué Pariona Pastrana.

3. Corte Suprema de Justicia, Sala Penal Permanente. (26 de julio de 2021), Casación N¹609-2019-Moquegua. MP. César San Martín Castro.

4. Günther Jakobs, Derecho Penal Parte General (Madrid: Marcial Pons, Ediciones Jurídicas, S.A, 1997), p. 267.

5. Ibídem, p. 266. 
De este modo, la distinción del sujeto y la actuación reglada que realiza para el Estado o sus instituciones es un componente esencial en la caracterización del delito de peculado, de esta manera, la Corte Suprema, en relación a la calidad del sujeto activo ha reafirmado que se trata de un sujeto especial y no, de uno indeterminado, confirmó la condena a un secretario de juzgado de la siguiente manera:

Óscar Merardo Asencio Bardales en su condición de secretario judicial del Primer Juzgado de Familia de la Corte Superior de Justicia de Cajamarca, al apropiarse de la cantidad de dos mil ochocientos veinte nuevos soles que pertenecía a los beneficiarios de los depósitos judiciales en los procesos que se encontraban bajo su responsabilidad, para cuyo efecto falsificó la firma de sus titulares e hizo entrega de estos títulos a la técnico judicial Sofía Cabrera Vargas a efectos de que los endose a Juliana Ortiz García y Margarita Alcántara Novoa y luego procedan a cobrarlos en las agencias del Banco de la Nación de Cajamarca ${ }^{6}$.

De igual modo, en la configuración de delito de peculado, el agente especial también infringe un deber especial que se corresponde con lo íntimo de su cargo, esto es, un deber que fundamenta la existencia del cargo estatal que en ese momento ocupa el agente. El cargo, cualquiera que fuere su rango, posición o ubicación, debe ejercerse de acuerdo con las normas de su creación, las que indudablemente no excluyen las finalidades que cumple el Estado en la sociedad. En ese marco, opinamos que el paso del agente por el cargo (que acuerda el artículo $425 \mathrm{CP}$ ) podría ser transitorio o la labor desarrollada, ser específica o, incluso, de naturaleza temporal, empero, esta situación, no le resta la calidad especial a quien lo ejercita, siempre que su relación con entidades u organismos del Estado, sea en el ejercicio de funciones públicas. De este modo, la Corte Suprema ha precisado que:

(...) [1]os imputados Alama Gallardo y Guerrero Castillo, así como Chanduví Vargas y Vásquez Atoche eran miembros del Consejo Universitario y su condición de órgano de gobierno universitario; y, en el caso concreto, desarrollaban funciones públicas con relación al examen de admisión de una Universidad Nacional-, que es un organismo del Estado, pese a lo cual vulneraron sus deberes institucionales mediante el pago de dinero y de este modo trataron de garantizar ilícitamente el ingreso a la Universidad Nacional de Piura, proporcionando a determinados postulantes las claves de las respuestas -artículo 425, inciso 3, del Código Penal ${ }^{7}$ (...)

\section{LA PARTICIPACIÓN EN EL EJERCICIO DE FUNCIONES PÚBLICAS Y AMPLITUD DEL TÉRMINO FUNCIONARIO PÚBLICO.}

El funcionario o servidor público no solo es aquel que realiza una función pública en relación de dependencia con el Estado o sus organismos, sino, también aquel que está vinculado con la administración de un bien público destinado a cumplir fines estatales, sea cual sea el nivel que ostente en el Cuadro Analítico de Personal. Desde otra perspectiva, Mir, propone los siguientes requisitos para ser considerado funcionario o servidor público:

6. Corte Suprema de Justicia, Sala Penal Permanente. (26 mayo de 2010), R.N. Nº738-2009-Cajamarca. MP. Hugo Príncipe Trujillo.

7. Corte Suprema de Justicia, Sala Penal Transitoria. (15 de enero de 2013), R.N. Nº1923-2012-Piura. MP. César San Martín Castro. 
(...) desde el Derecho penal se exige, entonces, para ser considerado funcionario o servidor público (i) un elemento referido a la participación en el ejercicio de funciones públicas; y (ii) un título de habilitación de dicha participación, que puede ser triple: disposición de la ley, elección o designación o nombramiento por autoridad competente -determinante de un vínculo con el Estado o sus entidades, incluidas empresas públicas o de economía mixta ${ }^{8}$.

La participación en el ejercicio de funciones públicas se corresponde con un concepto jurídico indeterminado que por su amplitud podría colisionar con el principio de legalidad e, inclusive, comprenderse a aquellas personas que coadyuvan a la función pública sin retribución alguna. La Corte Suprema de Justicia sobre los alcances del artículo 425 del Código Penal, que fija los lineamientos a seguir para identificar al funcionario o servidor público, ha puntualizado lo siguiente:

(...) el artículo 425 del Código Penal incorpora una noción amplia de funcionario o servidor público, pues no solo comprende a los que ingresan a la carrera administrativa, a los que desempeñan cargos políticos o de confianza y a los miembros de las Fuerzas Armadas y Policía Nacional; sino también (i) a los que, con independencia del régimen laboral, presten servicios en organismos públicos en general -incluidas empresas públicas y sociedades de economía mixta- y en su mérito ejerzan funciones en ellas, y (ii) a los designados por autoridad competente para desempeñar actividades o funciones en nombre o al servicio del Estado o sus entidades»; en ese sentido, -refiriéndose al Cuerpo General de Bomberos- se puntualizó que «es de analizar el status integral de su función, la naturaleza del servicio de la institución y las reglas jurídicas respecto de los bienes asignados para el cumplimiento de sus funciones (artículos 5 y 6 del (...) Decreto Legislativo [N 1260$]^{9}$.

En realidad, la amplitud del término funcionario público -no es un atributo único de la legislación nacional- viene dada por el carácter general que ha impuesto el legislador a ese término; lo que, según creemos, se debería a las múltiples formas en que se accede a este cargo y, fundamentalmente, al tipo de actividades o funciones públicas que se desempeña. Está característica también se presenta en el Código Penal español, lo que, según la doctrina estaría relacionado a la vaga noción de la frase «participación en funciones públicas», utilizada por el Código Penal español ${ }^{10}$.

Similar generalidad se observa en el caso de la legislación peruana, donde el artículo 425 del Código Penal, refiere un amplio catálogo de situaciones, posibilidades o estados en los que una persona puede ser considerada como funcionario o servidor público, donde lo resaltante es la existencia de un vínculo con las actividades, funciones o servicios que le corresponde brindar al Estado o sus entidades, bajo regímenes contractuales o laborales diferenciados. Por ejemplo, los designados por autoridad competente para desempeñar funciones al servicio del Estado. La designación, no es más que el nombramien-

8. Carlos Mir, op. cit. p. 22.

9. Corte Suprema de Justicia, Sala Penal Transitoria. (15 de enero de 2013), R.N. N¹923-2012-Piura. MP. César San Martín Castro.

10. Jesús-María Silva (Dir), Ramón Ragués, (Coord). Lecciones de Derecho Penal parte especial. (Barcelona: Atelier Libros Jurídicos, 2006), p. 304. 
to otorgado para desempeñar un cargo en el Estado, empero, para el supuesto del derecho penal, la atribución que se hace al término designación es el acto de autoridad necesario para ser considerado funcionario público. En ese sentido, la designación es el título que posibilita el ejercicio de la función pública. Lo cual viene relacionado con el llamado título de habilitación, que es el requisito que debe observar una persona para ser considerada funcionario o servidor público.

Al respecto, Montoya, Chanján, Novoa, Rodríguez y Quispe ${ }^{11}$ precisan que «[1]a incorporación heterónoma a la función pública significa que el funcionario público adquiere su estado a través de una acción de selección, nombramiento o elección por el pueblo, la norma, o una persona que -distinta al propio funcionario- ostente el poder suficiente para vincular al nuevo servidor con la administración pública», «justamente es la existencia del título legitimante la que da origen al ejercicio de la función pública» $^{12}$

De acuerdo con la Corte Suprema de Justicia, la designación, nombramiento o conferimiento de la función se puede realizar hasta de manera verbal; sin embargo, es imprescindible este requisito -aunque irregular-, pues caso contrario se colegiría que cualquier ciudadano, sin vinculación con la Administración Pública, puede constituirse como funcionario de hecho, lo cual es un absurdo; máxime si existen otros tipos penales destinados a sancionar la conducta de particulares que usurpan funciones públicas ${ }^{13}$. De la lectura de la misma, se entiende que el título habilitante es un elemento indispensable para el ejercicio de la función pública en calidad de funcionario público, el cual incluye las incorporaciones otorgadas verbalmente, aunque esto último podría ser considerado irregular, empero, penalmente, se hace indispensable. Es el caso de una persona que hubiere sido designada por el alcalde de una provincia como gerente municipal, mediante Resolución de Alcaldía, por lo tanto, cuenta con un título habilitante. En ese sentido, la Corte Suprema de Justicia, ha seńalado que los gerentes municipales son sujeto activo del delito de peculado, por cuanto, tienen la condición de funcionario o servidor público ${ }^{14}$.

\section{EL FUNCIONARIO DE HECHO}

La apertura dada por la jurisprudencia al término funcionario público, así como las diversas maneras en que el derecho penal acepta la designación en el cargo, ha dado como consecuencia, el acogimiento del funcionario de hecho como titular de la acción punible en el delito de peculado. El funcionario de

11. Yvan Montoya, Rafael Chanján, Yvana Novoa, Julio Rodríguez y Fanny Quispe, Manual de capacitación para operadores de justicia en delitos contra la administración pública. (Lima: Instituto de Democracia y Derechos Humanos de la Pontificia Universidad Católica del Perú, IDEHPUCP, primera edición, 2013), p.33.

12. Francisco Heydegger y Jhuliana Atahuamán (Coord), Delitos contra la Administración Pública. (Lima: Centro de Estudios Penales. IDEMSA, 2013), p. 77.

13. Corte Suprema de Justicia, Sala Penal Transitoria. (11 de diciembre de 2019), Casación N442-2017-Ica. MP. Iris Pacheco Huancas.

14. Corte Suprema de Justicia, Sala Penal Permanente. (15 de mayo de 2019), Casación Nº1500-2017-Huancavelica. MP. César San Martín Castro. 
hecho o de facto es aquel funcionario público que desempeña en la práctica una función púbica para la cual no fue formalmente habilitado de manera inequívoca ${ }^{15}$, también se ha dicho que funcionario de facto es aquel que no cuenta con los requisitos legales exigidos para el cargo suscitada de buena fe, pero, también se es por cese, destitución o terminación o abandono, donde el continuar ejerciendo funciones lo convierte en funcionario de facto o en usurpador ${ }^{16}$.

El nombramiento irregular o defectuoso y el ejercicio de una función pública específica son dos puntos importantes que resalta la doctrina extranjera, bajo esta percepción, Muñoz ${ }^{17}$, señala que funcionario de hecho, es el que, habiendo sido nombrado o elegido, no reúne las condiciones necesarias para ello, empero, para efectos penales, es considerado funcionario público. Soler ${ }^{18}$, indica que funcionario de facto, es aquel que como funcionario actúa y que esa actuación solamente es posible o por consentimiento de órganos superiores o por descuido de estos. En ambos casos [en referencia al usurpador de cargo público], el sujeto presenta el aspecto del funcionario legal, por lo que el pago hecho a él en buena fe, es un pago hecho al fisco y, en consecuencia, la substracción que aquél ejecute es peculado (lo escrito entre corchetes es nuestro). Creus ${ }^{19}$, señala que el título defectuoso o del nombramiento con vicios formales, pero expedidos por la autoridad competente, pueden dar lugar a la figura del llamado funcionario de facto, que no es un usurpador. Terradillos ${ }^{20}$, precisa que es condición de eficacia de las estrategias anticorrupción que, [el término funcionario público] lejos de limitarse al aparato administrativo, se extiendan a todos los agentes que, de facto, tienen facultades de decisión en la materia. (Lo escrito entre corchetes es nuestro). Rodríguez ${ }^{21}$, precisa que se trata de un particular que es incorporado como funcionario público a través de alguna forma de selección, designación o nombramiento que podrá resultar nulo, anulable y/o inexistente.

Sin embargo, la doctrina nacional no es uniforme en cuanto a la aplicación de la teoría del funcionario de hecho a nuestra realidad. Alcocer ${ }^{22}$, puntualiza que la figura del administrador de hecho no

15. Rafael Chanjan, Maricielo Aranda, Scarlett Motta, María Fourment y Ana Retuerto. "Señora procuradora pública de la procuraduría pública ad hoc del caso Odebrecht" https://cdn01.pucp.education/idehpucp/wp-content/ uploads/2021/03/08215655/Anexo-16.pdf

16. Fidel Rojas, Delitos contra la Administración Pública, (Lima: Editorial Grijley, cuarta edición, 2007), p.42.

17. Francisco Muñoz, Derecho Penal Parte Especial, (Valencia: Tirant lo Blanch. 18 edición, 2010), p. 986.

18. Sebastián Soler, Derecho Penal argentino. Tomo V. (Buenos Aires: Tipográfica Editora argentina, 1978), p. 181.

19. Carlos Creus, Derecho Penal Parte Especial. Tomo 2, (Buenos Aires: Editorial Astrea, Sexta edición actualizada y ampliada, 1era. Reimpresión, 1998), p. 241.

20. Juan María Terradillos, “Corrupción Política: Consideraciones Político Criminales”, Revista Electrónica de Estudios Penales y de la Seguridad ISSN: 2531-1565.

21. Ana Rodríguez, citada por Yván Montoya (Coord). Manual sobre delitos contra la Administración Pública. Lima: Instituto de Democracia y Derechos de la Pontificia Universidad Católica del Perú. Primera edición, 2015), p. 42.

22. Eduardo Alcocer. La autoría y participación en el delito de peculado. Comentarios a partir del caso MontesinosBedoya. Instituto de Ciencia Procesal Penal, p. 9. http://files.escuelalibredederecho.webnode.es/200000035-f07c8f176e/ PECULADO\%20-\%20http---www.incipp.org.pe-archivos-publicaciones-peculadoalcocer.pdf 
resulta aplicable a los delitos que, como el peculado, aluden a la infracción de un deber y no al dominio de hecho, por cuanto, lo fundamental en esta cuestión [administrador de hecho] no es la calificación formal o jurídica que se le otorga al sujeto activo, sino la posibilidad fáctica que ostenta para poder cometer el delito, basado principalmente, en el dominio efectivo, y lesionar así el bien jurídico protegido. Desde otro punto de vista, Nakazaki ${ }^{23}$, niega la posibilidad de aplicar la teoría del funcionario de hecho con prescindencia del principio de legalidad, puesto que limita las facultades punitivas dentro de un Estado de Derecho. Según, Chanján ${ }^{24}$, los aspectos formales referidos al acceso al cargo no son obstáculos para considerar penalmente responsable a quien los ejerce.

Por otro lado, la Corte Suprema, en la Casación N442-2017-Ica, considera que la doctrina y jurisprudencia nacional, han asumido la posición restringida de funcionario de hecho, en ese sentido, acogiendo la definición proporcionada por De La Vallina, señala que funcionario de hecho será aquel que ejerciendo las funciones públicas propias de un oficio o cargo público, le falta algún requisito fundamental para hacer de él un funcionario de iure, sin embargo, la persona así ingresada al servicio público, sí realiza una labor efectiva y actúa en el cargo que no le corresponde como si su origen fuere legítimo ${ }^{25}$. Por tanto, en lo que a la doctrina nacional se refiere, mayoritariamente, se admite la categoría del funcionario de hecho o de facto como agente del delito de peculado.

El funcionario de hecho es una categoría no prevista por la ley penal. Su aparición en el ámbito nacional se debe a la jurisprudencia que atribuye a este funcionario la calidad de sujeto activo del delito de peculado. Nosotros, opinamos que el funcionario de hecho es aquel que, sin estar nombrado expresamente para ejercer un determinado cargo público, es tácitamente reconocido como tal y por asentimiento o reconocimiento informal (pero expreso) de un funcionario superior o de mayor rango a aquel que cuenta con legitimación, en mérito a lo cual, en la práctica, el así designado ejerce las atribuciones del cargo público que -tácitamente- se le ha conferido. El punto que identifica al funcionario de hecho o de facto está en el ejercicio material de la función pública de un cargo con el que no cuenta con la debida designación. Por ello, los defectos en el nombramiento, no impide que se le trate, para los efectos penales, como funcionario público. Sin embargo, con defectos o no en la designación del funcionario, esta tiene que darse, puesto que la falta absoluta del acto de consentimiento por el Estado -sin título alguno-, daría como consecuencia estar al frente de un supuesto fáctico de usurpación de funciones y

23. César Nakazaki. "Problemas de aplicación de la figura del funcionario de hecho en la doctrina judicial del sub sistema de justicia anticorrupción del Perú”, p.13.

https://www.snakazaki.com/storage/app/uploads/public/595/5c5/7af/5955c57af2410318822506.pdf

24. Rafael Chanján. "Reflexiones en torno al "funcionario de facto" en el derecho penal: a propósito del caso de la ex primera dama Nadine Heredia”. https://idehpucp.pucp.edu.pe/notas-informativas/reflexiones-en-torno-al-funcionario-de-facto-en-el-derecho-penal-a-proposito-del-caso-de-la-ex-primera-dama-nadine-heredia/

25. Corte Suprema de Justicia, Sala Penal Transitoria. (11 de diciembre de 2019), Casación N²442-2017-Ica. MP. Iris Pacheco Huancas. 
no al de funcionario de hecho ${ }^{26}$. Este ejercicio material de la función se corresponde con el desempeño de un cargo específico, por tanto, el agente del delito de peculado no toma los bienes patrimoniales a cargo de otro, sino, solo aquellos sobre los que recae el poder que se le ha conferido, por cuanto, estos últimos le han sido confiados por razón de su cargo, sin embargo, defrauda la confianza dada por el Estado, desconoce el dominio del titular y se coloca en la posibilidad de disponer de ellos como si fuere propietario. En ese sentido, creemos que el agente abusa de la función y del poder de disposición o manejo de los bienes que ostenta, cuya percepción, administración o custodia le estén confiados ${ }^{27}$.

\section{LA VINCULACIÓN FUNCIONAL}

Los bienes (caudales o efectos) confiados en razón al cargo, son aquellos que, por ejemplo, se entregan al servidor público y que son aptos para que pueda desempeñar su función ${ }^{28}$, y cumplir su prestación, sin embargo, para que se perfeccione el delito de peculado, se requiere comprobar que existe una vinculación funcional del sujeto con respecto a los caudales y efectos públicos ${ }^{29}$. La Corte Suprema ${ }^{30}$, atribuye a la frase relación funcional, el poder de vigilancia y control sobre la cosa como mero componente típico, esto es, competencia del cargo, confianza en el funcionario en virtud del cargo, el poder de vigilar y cuidar los caudales o efectos. Este afán relacional entre sujeto y objeto material lo podemos observar en la siguiente Ejecutoria Suprema:

El procesado Montesinos, al disponer de los fondos que administraba de hecho y fueron entregados para favorecer a terceros, permite colegir que existía una relación funcional entre el citado procesado con los recursos públicos, lo cual implicaba un deber de custodia y correcta administración por ser un patrimonio que pertenecía al Estado; por lo que al financiar la campańa de su coprocesado Bedoya de Vivanco, incurrió en el delito de peculado en calidad de autor, (Corte Suprema de Justicia (2003) citada por León) ${ }^{31}$.

De otra parte, contra la sentencia de la Segunda Sala Penal para Procesos con Reos Libres de la Corte Superior de Justicia de Lima de fecha 4 de junio de 2004, el sentenciado Luis Guillermo Bedoya de Vivanco interpuso Recurso extraordinario, en el que el Tribunal Constitucional, dijo:

26. José Nolasco y Erika Ayala. Delitos contra la Administración Pública. Tomo I. (Lima: Ara Editores, 2013), p. 136.

27. Cfr. Francisco Ferreira, Delitos contra la Administración Pública, (Santa Fe de Bogotá: Editorial Temis S.A. Tercera edición actualizada, 1995), p. 19.

28. Francisco Ferreira, op. cit. pp. 20-21.

29. James Reátegui, Delitos contra la Administración Pública en el Código Penal. (Lima: Juristas editores E.I.R.L. 2015), p. 430 .

30. Corte Suprema de Justicia, Salas Penales Permanente y Transitoria (Acuerdo Plenario Nº4-2005/CJ-116 de fecha 30 de setiembre de 2005. Definición y estructura típica del delito de peculado. Art. 387 C.P), MP. Gonzales Campos.

31. Vladimir León, Hesbert Benavente, Leonardo Calderón, El Funcionario Público. Las Sanciones Penales en los Delitos de Corrupción. (Lima: Gaceta jurídica, Primera edición, 2015), p 24. 
Este Tribunal coincide con lo señalado en la sentencia cuestionada en el sentido de que sí se configura, en el caso, el delito de peculado. Si bien es cierto que formalmente Vladimiro Montesinos Torres ocupaba el cargo de Asesor II de la Alta Dirección del Servicio de Inteligencia Nacional, en realidad, ejercía, de hecho, la Jefatura del SIN, cargo que le permitía la custodia y administración de fondos públicos, por lo que puede considerarse sujeto activo del delito, tal como lo prevé el artículo 387 del Código Penal ${ }^{32}$.

En fin, la frase «por razón del cargo» no puede ser interpretada en sentido lato, esto es, de que cualquier funcionario público quedará vinculado a la entrega o custodia de los caudales o efectos públicos, aunque sea por circunstancia ocasional ${ }^{33}$, sino, este componente normativo tiene que ser verificado en el sector social donde se desenvuelve la conducta del autor por las normas que regulan dicho segmento -ley de la materia, ROF, MOF, etc.-, en otras palabras, el tipo penal de peculado hace referencia a un funcionario público no in abstracto, sino contextualizado a un segmento concreto de la función pública "por razón de su cargo" 34 , de lo que se deduce que el agente del peculado no cumple el rol social para el que se le designó, por el contrario, realiza actos de disposición sobre los caudales o efectos que la ley no permite.

\section{VI. ÁNIMO DE LUCRO, DESBALANCE PATRIMONIAL Y CUANTÍA MÍNIMA.}

Dentro del ámbito estrictamente legal, la consumación del delito de peculado, no requiere ánimo de lucro en el sujeto activo, tampoco, que se produzca un desbalance patrimonial en las arcas del Estado, pues, si así fuere, no se podría comprender en este delito a ningún servidor público que se apropia para sí o para un tercero del algún bien público que le ha sido entregado para ejercer su labor cotidiana y cumplir una parte de la función -del universo funcional que ostenta el Estado- que le ha sido encomendada como integrante de un organismo estatal, sino tendría que verificarse el ánimo de lucro y el desbalance patrimonial. Lo que sí se exige es que la apropiación determine que el bien público se incorpore al ámbito dominial del agente o de un tercero ${ }^{35}$, no necesariamente que incremente su patrimonio, aunque a veces sea así. Este es un delito de infracción de deber, puesto que la sanción se presenta cuando el agente, en lugar de administrar correctamente (para la función encomendada) los bienes que no son de él (deber), se aparta de la facultad de administración y adopta un comportamiento de dueño. Por tanto, lo que se reprime es esa falta de compromiso del servidor público con su deber de administración y lealtad, cuando esto se da, aparece el hecho ilícito. Aun cuando se presente un atisbo patrimonial debido al objeto sobre el cual recae la acción material del sujeto activo, no es un delito

32. Tribunal Constitucional, (23 de noviembre de 2004). Expediente $\mathrm{N}^{\circ} 2758-2004-\mathrm{HC} / \mathrm{TC}-\mathrm{Lima}$.

33. James Reátegui, op. cit. p. 430.

34. Corte Suprema de Justicia, Sala Penal Permanente. (16 de agosto de 2016), R.N. N615-2015- Lima. MP. Josué Pariona Pastrana.

35. Los actos de dominio pueden manifestarse mediante la disposición del bien estatal. La Corte Suprema ha dicho que el sujeto se apropia de los bienes públicos cuando la aparta del ámbito de custodia de la Administración pública. Corte Suprema de Justicia. Sala Penal Permanente. (29 de abril de 2019), R.N. N²124-2018-Lima. MP. César San Martín Castro. 
contra el patrimonio: se trata de un delito de infracción de deber en el ámbito de la Administración Pública ${ }^{36}$, debido a ello, y porque la ley no lo contempla, no es posible atribuir a este delito un carácter de ánimo de lucro o desbalance patrimonial como componentes del mismo, porque estos no son sus elementos típicos objetivos ni subjetivos. Si el delito de peculado defiende al Estado de sus funcionarios o servidores que desencadenan un forado en el desenvolvimiento del servicio público que brinda y no prevé cuantía alguna, como tampoco es necesario que el agente obtenga un provecho económico ${ }^{37}$, entonces, ante el apoderamiento de bienes de valor insignificante, lo que se espera, es la imposición de la sanción prevista legalmente, aunque de escasa entidad. Sin embargo, en estos casos, la Corte Suprema antepone el valor de los caudales afectados, sin meditar, según creemos, puntualmente, en la infracción del deber incurrido -que lo identifica-, y en las consecuencias que ello genera al servicio público, bajo esa línea argumentativa, Cáceres, nos proporciona la siguiente resolución:

El delito de peculado no se encuentra comprendido dentro de los delitos contra el patrimonio, sino, antes bien, como delito cometido contra la administración pública por funcionario público, donde el bien jurídicamente tutelado es la correcta utilización de los fondos o efectos estatales encomendados (Ejecutoria Suprema de fecha 14 de abril de 2000. Expediente $\mathrm{N}^{\circ} 1132-98$-Lima) ${ }^{38}$.

De este modo, trasladar la línea telefónica de la Municipalidad de la cual se es alcalde y efectuar

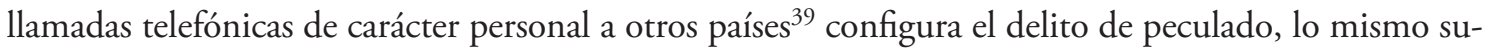
cede cuando los trabajadores de una Municipalidad Provincial, encargados de la vigilancia del depósito municipal se apropian de un alternador y de un relay correspondientes al vehículo que recibieron en custodia $^{40}$, aun cuando su valor es irrisorio. Esta razón ha sido considerada por la Corte Suprema de Justicia en la siguiente resolución:

36. «Los delitos que se integran bajo el capítulo del peculado son conductas contra la administración pública (bien jurídico tutelado) pues se considera que una mala administración de los bienes confiados al servidor público, en razón o con ocasión de sus funciones, incide en forma negativa en la correcta administración del Estado por deformación del instituto real "pues además del patrimonio público también lesiona los servicios que mediante este han de prestarse a la comunidad”». Cita de Salvador Vives Antón en Lombana Villalba, Manual de Derecho Penal; 2011; Pág. 238, citado por Juanita María Ospina Perdomo. Tipologías de Corrupción en Colombia. Peculados. Tomo II. (Unidos contra la Corrupción para el Desarrollo, la Paz y la Seguridad. Fiscalía General de la Nación. Oficina de las Naciones Unidas contra la Droga y el Delito).

37. Corte Suprema de Justicia. Segunda Sala Penal Transitoria. (17 de marzo de 2017), R.N. N525-2015-Ayacucho. MP. Zavina Magdalena Luisa Chávez Mellá.

38. Roberto Cáceres, El delito de peculado. Aspectos sustantivos y procesales. (Lima: Idemsa, Primera edición, 2012), p. 31

39. Corte Suprema de Justicia, Sala Penal Permanente. (13 de febrero de 2014), R.N. N³004-2012-Cajamarca. MP. Josué Pariona Pastrana.

40. Corte Suprema de Justicia, Sala Penal Permanente. (19 de marzo de 2010), R.N. N²38-2009-Puno. MP. Jorge Calderón Castillo. 
En nuestra legislación penal, en los delitos cometidos por funcionarios públicos - peculado- no se requiere establecer la naturaleza penal de los hechos en vía extrapenal, ya que en estos delitos no importa la cuantía de los caudales públicos apropiados o ilícitamente utilizados, configurándose este cuando los bienes estatales son usados para fines ajenos al servicio y realizados por funcionario o servidores públicos $(. . .)^{41}$.

Es de precisar que esta posición -de clasificar al delito de peculado como un delito de infracción de deber- no niega el carácter pluriofensivo que ostenta el delito de peculado, donde la infidelidad en la administración del patrimonio público y la conducta deshonesta y abusiva del hombre público salta a la vista, direccionada a perjudicar las altas razones de conservar el patrimonio de todos los connacionales.

\section{CONCLUSIONES}

1. La jurisprudencia nacional ha acogido un concepto amplio del término funcionario público previsto en el artículo 425 del Código Penal, donde la designación para el ejercicio de la función o el servicio público puede provenir de un acto verbal de un sujeto legitimado para efectuarlo, siendo este el título habilitante.

2. La Corte Suprema, en el caso de utilización de bienes públicos de escaso valor, sin dejar de reconocer que se trata de una conducta reprochable, se ha pronunciado por aplicar el principio de mínima intervención y el principio de lesividad ${ }^{42}$.

3. La Corte Suprema, ha estatuido que en el delito de peculado el agente público no solo lesiona los intereses patrimoniales de la Administración Pública, sino, además, abusa del poder conferido, con lo que quebranta los deberes de lealtad y probidad que guían la función pública. (Acuerdo Plenario $\mathrm{N}^{\circ}$ 4-2005/CJ-116).

\section{REFERENCIAS}

- Alcocer, Eduardo. s/f. La autoría y participación en el delito de peculado Comentarios a partir del caso Montesinos- Bedoya.

- Cáceres, Roberto. El delito de peculado. Aspectos sustantivos y procesales. Lima: Idemsa, primera edición, 2012.

- Corte Suprema de Justicia, Sala Penal Permanente. Casación N¹609-2019-Moquegua.

- $\quad$ Corte Suprema de Justicia, Sala Penal Permanente. Recurso de Nulidad No 738-2009Cajamarca.

- $\quad$ Corte Suprema de Justicia, Sala Penal Transitoria. Recurso de Nulidad No 1923-2012-Piura.

41. Corte Suprema de Justicia, Sala Penal (13 de enero de 2004), R.N. N³682-2002-La Libertad. MP. Isaac Gamero Valdivia.

42. La Convención Interamericana y la Convención de las Naciones Unidas contra la Corrupción, estatuyen que su aplicación no requiere que los actos de corrupción que ella enuncia produzcan perjuicio patrimonial al Estado o produzcan daño patrimonial al Estado. 
- $\quad$ Corte Suprema de Justicia, Sala Penal Transitoria. Casación N442-2017-Ica.

- Corte Suprema de Justicia, Sala Penal Permanente. Casación Nº 1500-2017-Huancavelica.

- Corte Suprema de Justicia, Sala Penal Permanente. Recurso de Nulidad Nº 615-2015- Lima.

- $\quad$ Corte Suprema de Justicia. Segunda Sala Penal Transitoria. R.N. N525-2015-Ayacucho.

- $\quad$ Corte Suprema de Justicia, Sala Penal Permanente. R.N. N³004-2012-Cajamarca.

- $\quad$ Corte Suprema de Justicia, Sala Penal Permanente. R.N. N²38-2009-Puno.

- $\quad$ Corte Suprema de Justicia, Sala Penal. R.N. N³682-2002-La Libertad.

- Convención Interamericana contra la Corrupción.

- Convención de las Naciones Unidas contra la Corrupción.

- Creus, Carlos. Derecho Penal Parte Especial. Tomo 2. Buenos Aires: Editorial Astrea, sexta edición actualizada y ampliada, 1era reimpresión,1998.

- Chanján, Rafael. "Reflexiones en torno al "funcionario de facto" en el Derecho Penal: a propósito del caso de la ex primera dama Nadine Heredia".

- Chanjan Rafael, Aranda Maricielo, Motta Scarlett, Fourment María y Retuerto Ana. "Señora procuradora pública de la procuraduría pública ad hoc del caso Odebrecht"

- Ferreira, Francisco. Delitos contra la Administración Pública. Santa Fe de Bogotá: Editorial Temis S.A. Tercera edición actualizada, 1995.

- Heydegger, Francisco, Atahuamán, Jhuliana. (coordinadores). Delitos contra la Administración Pública. Lima: Centro de Estudios Penales. IDEMSA, 2013.

- Jakobs, Günther. Derecho Penal Parte General. Traducción de Joaquín Cuello Contreras, José Luis Serrano Gonzales de Murillo. Madrid: Marcial Pons, Ediciones Jurídicas, S.A. $2^{\circ}$ edición, corregida, 1997.

- $\quad$ León, Vladimir, Benavente Hesbert, Calderón Leonardo. El Funcionario Público. Las Sanciones Penales en los Delitos de Corrupción. Lima: Gaceta jurídica, Primera edición, 2015.

- Mir, Carlos. Delitos contra la Administración Pública en el Nuevo Código Penal. Barcelona: José María Bosh editor, 2000.

- Montoya, Yván, Chanjan Rafael, Novoa Y., Rodríguez J., Quispe F. Manual de Capacitación para operadores de justicia en delitos contra la administración pública. Lima: Instituto de Democracia y Derechos Humanos de la Pontificia Universidad Católica del Perú (IDEHPU CP), Primera edición, 2013. 
- Muñoz, Francisco. Derecho Penal Parte Especial. Valencia: Tirant lo Blanch, $18^{\circ}$ edición, revisada y puesta al día, 2010.

- Nakazaki, César. Problemas de aplicación de la figura del funcionario de hecho en la doctrina judicial del sub sistema de justicia anticorrupción del Perú.

Chrome-extension://efaidnbmnnnibpcajpcglclefindmkaj/viewer.html?pdfurl=https $\% 3 \mathrm{~A}$

\%2F\%2Fwww.snakazaki.com\%2Fstorage\%2Fapp\%2Fuploads\%2Fpublic\%2F595\%2

F5c5\%2F7af\%2F5955c57af2410318822506.pdf\&clen=467411\&chunk=true

- Nolasco, José, Ayala Erika. Delitos contra la Administración Pública. Tomo I. Lima: Ara

Editores, 2013.

- Ospina, Juanita. Tipologías de Corrupción en Colombia. Peculados. Tomo II. (Unidos contra la Corrupción para el Desarrollo, la Paz y la Seguridad. Fiscalía General de la Nación.

Oficina de las Naciones Unidas contra la Droga y el Delito).

https://www.fiscalia.gov.co/colombia/wp-content/uploads/Tomo-II.pdf

- Pleno Jurisdiccional de las Salas Penales Permanente y Transitoria de la Corte Suprema de Justicia de la República. (30 de setiembre de 2005). Acuerdo Plenario No 4-2005/CJ-116. Asunto: Definición y estructura del delito de peculado.

- Reátegui, James. Delitos contra la Administración Pública en el Código Penal. Lima: Juristas editores E.I.R.L. 2015.

- Rojas, Fidel. Delitos contra la Administración Pública. Lima: Editorial Grijley, 4ta edición, 2007.

- Silva, Jesús-María (Dir), Ragués, Ramón. (Coord). Lecciones de Derecho Penal parte especial. Barcelona: Atelier Libros Jurídicos, 2006.

- Soler, Sebastián. Derecho Penal argentino. Tomo V. Buenos Aires: Tipográfica Editora argentina, 1978.

- Terradillos, Juan María. "Corrupción Política: Consideraciones Político Criminales”. Revista Electrónica de Estudios Penales y de la Seguridad ISSN: 2531-1565.

- Tribunal Constitucional. (23 de noviembre de 2004). Expediente $\mathrm{N}^{\circ}$ 2758-2004-HC/TC Lima. Caso: Bedoya de Vivanco.

RECIBIDO: $27 / 10 / 2021$

APROBADO: $30 / 10 / 2021$ 